ARTICLE

DOI: $10.1038 / s 41467-016-0014-9$

\title{
GIGANTEA is a co-chaperone which facilitates maturation of ZEITLUPE in the Arabidopsis circadian clock
}

Joon-Yung Cha', Jeongsik Kim²,3, Tae-Sung Kim²,4, Qingning Zeng ${ }^{2}$, Lei Wang (id ${ }^{2,5}$, Sang Yeol Lee ${ }^{1}$, Woe-Yeon $\mathrm{Kim}^{1} \&$ David E. Somers ${ }^{2}$

Circadian clock systems help establish the correct daily phasing of the behavioral, developmental, and molecular events needed for the proper coordination of physiology and metabolism. The circadian oscillator comprises transcription-translation feedback loops but also requires post-translational processes that regulate clock protein homeostasis. GIGANTEA is a unique plant protein involved in the maintenance and control of numerous facets of plant physiology and development. Through an unknown mechanism GIGANTEA stabilizes the F-box protein ZEITLUPE, a key regulator of the circadian clock. Here, we show that GIGANTEA has general protein chaperone activity and can act to specifically facilitate ZEITLUPE maturation into an active form in vitro and in planta. GIGANTEA forms a ternary complex with HSP9O and ZEITLUPE and its co-chaperone action synergistically enhances HSP90/HSP70 maturation of ZEITLUPE in vitro. These results identify a molecular mechanism for GIGANTEA activity that can explain its wide-ranging role in plant biology.

\footnotetext{
${ }^{1}$ Division of Applied Life Science (BK21Plus), PMBBRC \&IALS, Gyeongsang National University, Jinju 52828, Republic of Korea. ${ }^{2}$ Department of Molecular Genetics, The Ohio State University, Columbus 43210, USA. ${ }^{3}$ Present address: Center for Plant Aging Research, Institute for Basic Science (IBS), Daegu 711-873, Republic of Korea. ${ }^{4}$ Present address: Department of Agricultural Sciences, Korea National Open University, Seoul 03087, Republic of Korea. ${ }^{5}$ Present address: Key Laboratory of Plant Molecular Physiology, Institute of Botany, Chinese Academy of Sciences, Beijing 100093, China. Joon-Yung Cha and Jeongsik Kim contributed equally to this work. Correspondence and requests for materials should be addressed to W.-Y.K. (email: kim1312@gnu.ac.kr) or to D.E.S. (email: somers.24@osu.edu)
} 
T he circadian system is a $24 \mathrm{~h}$ timing mechanism common to most organisms on earth. Through a combination of transcriptional, translational, and post-translational processes, the circadian clock controls the phasing of gene expression, metabolism, and physiology to help optimize an organism's fit to its environment. In Arabidopsis, a mutually repressive negative feedback loop comprising the evening-expressed gene of TIMING OF CAB EXPRESION 1 (TOC1) and morningexpressed genes CIRCADIAN CLOCK ASSOCIATED 1/LATE ELONGATED HYPOCOTYL (CCA1/LHY) is one of the core components of the oscillator. Additional transcriptional repressors/co-repressors (PSEUDO-RESPONSE REGULATOR (PRR) 5, 7 and 9, TOPLESS (TPL), LUX ARRHYTHMO (LUX)) and activators/co-activators (REVEILLE (RVE) 4, RVE6, NIGHT LIGHT-INDUCIBLE AND CLOCK-REGULATED 1(LNK1), LNK2) are further necessary in establishing both proper period and robustness of the circadian clock ${ }^{1}$.

In all known circadian systems both post-transcriptional and post-translational processes are essential to clock function ${ }^{2-4}$. In Arabidopsis the F-box protein ZEITLUPE (ZTL) specifies an evening-phased E3 ubiquitin ligase (SCF ${ }^{\mathrm{ZTL}}$ ) that targets TOC1 and PRR5 for proteasomal degradation ${ }^{5-7}$. ZTL and related family members (FKF1 and LKP2) are unique among known F-box proteins in possessing a blue-light sensing domain [LIGHT, OXYGEN, VOLTAGE (LOV)] at the N-terminus, which facilitates their stability ${ }^{8}$. The large $(1173 \mathrm{aa})$ single-gene encoded protein, GIGANTEA (GI) interacts with the ZTL LOV domain to post-translationally stabilize ZTL in blue light ${ }^{9}$. Circadian oscillations of GI mRNA ${ }^{10,11}$ result in an eveningphased peak in GI protein abundance, which establishes and sustains a rhythm of ZTL abundance that is in phase with GI cycling 9 ,12. These oscillations in ZTL help maintain high-amplitude oscillations of TOC1 and PRR $5^{6,9}$.

Among the components required to sustain the plant circadian oscillator, GI is one of the few for which no molecular or biochemical function has been determined. It is highly conserved among vascular plants (Supplementary Fig. 1) 13 $^{13}$ and plays numerous roles in plant physiology and development, including the control of flowering time, hypocotyl elongation, circadian period, carbohydrate metabolism, salt tolerance, and other physiological processes ${ }^{14-19}$. Certain gi mutant alleles exhibit diametrically opposite phenotypes, indicating clearly separable roles for GI, and complexity and nuance in its many functions in the plant $11,19-21$. GIGANTEA mRNA and protein are clock-controlled and GI is found both in the cytosol and nucleus ${ }^{9-11,14,20,22,23}$. Under diurnal conditions GI forms unique nuclear bodies with EARLY FLOWERING 4 (ELF4) that dynamically oscillate in abundance ${ }^{24}$. GI protein regulation is poorly understood, but interaction with EARLY FLOWERING 3 (ELF3) and CONSTITUTIVE PHOTOMORPHOGENIC 1 (COP1) affects GI stability, and GI levels drop in the absence of ZTL ${ }^{22,25}$.

The fully functional state of all proteins requires correct threedimensional folding either during or shortly after synthesis. In the highly protein-dense cellular environment misfolded proteins may form into unproductive aggregates. To prevent such nonnative associations and to facilitate protein folding, cells possess a wide range of molecular chaperones that are essential to the proper maturation of a substantial number of proteins. Molecular chaperones can be defined as any protein that interacts, stabilizes, or helps a non-native protein to acquire its native conformation but is not present in the final functional structure ${ }^{26,27}$. These include the well-known and ubiquitous HSP70 and HSP90 chaperone systems, and the extensive chaperonin family (e.g., GroEL in bacteria; Cpn60 in chloroplasts) ${ }^{28,29}$. Co-chaperones are additional protein factors that pair with specific chaperones to confer specificity to the individual protein targets (clients) ${ }^{30,31}$.
Here we establish the molecular function of GI as a chaperone/ co-chaperone that associates with HSP90 to facilitate ZTL maturation into a fully functional protein in vitro and in vivo. GI forms a ternary complex with HSP90 and ZTL and synergistically enhances the effectiveness of the HSP70/HSP90-mediated maturation of ZTL. These findings suggest that the wide-ranging role of GI in plant biology may arise from its function as a co-chaperone that helps specify particular HSP90 clients from the extremely broad spectrum of proteins subject to the HSP90 chaperone cycle.

\section{Results}

GI exhibits general chaperone activity in vitro. Previous work demonstrated that both HSP90 and GI are required for ZTL protein accumulation and that ZTL is a client of the chaperone HSP $90^{9,32}$. These findings suggested that GI and HSP90 might co-regulate ZTL in the same pathway and act similarly and together. Whereas HSP90 is constitutively expressed, the circadian and diel oscillations in GI expression could consequently confer post-translational oscillations in ZTL levels by contributing to the maturation and stabilization of ZTL polypeptide.

To investigate a potential role for GI as a molecular chaperone, we first tested GI for general chaperone ability. Molecular chaperones possess a certain set of properties, some of which can be tested in vitro using generic substrates. These include the ability to recognize and bind unfolded proteins, to suppress aggregation during protein unfolding and folding, to influence the yield of folding, and to perform the second and third functions at stoichiometric levels ${ }^{26}$. The holdase concept tests whether the second property of a candidate chaperone-the ability to bind the substrate and inhibit aggregation-is satisfied. Generic model substrates such as malate dehydrogenase $(\mathrm{MDH})^{33-35}$, citrate synthase, and others are used to routinely to test this in vitro, as peptide binding studies with different chaperones show that most exhibit a greater preference for hydrophobic peptides than for charged, hydrophilic peptides ${ }^{26,35}$.

Adequate amounts of full-length, soluble GI could not be purified from Escherichia coli (E. coli), but an extensive GI $\mathrm{N}$-terminal polypeptide (aa $1-858,73 \%$ of the protein; $\mathrm{GI}^{\mathrm{N}}$ ) that includes a functional ZTL-interaction domain ${ }^{18}$ was successfully obtained. We first tested $\mathrm{GI}^{\mathrm{N}}$ by transient expression in planta for two key aspects of GI effects on ZTL: interaction specificity and stabilization. First, HA-GI ${ }^{\mathrm{N}}$ was able to recapitulate the specificity of full-length GI-ZTL protein interactions (co-immunoprecipitation) in Nicotiana benthamiana transient expression assays (Supplementary Fig. 2). The photochemically dead ZTL ${ }^{\mathrm{C} 2 \mathrm{~A}}$ allele interacts poorly with full-length GI and the same was found for $\mathrm{GI}^{\mathrm{N}}$ (Supplementary Fig. 2). Second, ZTL protein abundance was enhanced when $\mathrm{GI}^{\mathrm{N}}$ was transiently coexpressed with ZTL in Arabidopsis protoplasts. This was to the same extent as obtained for full-length GI and both polypeptides more poorly stabilized ZTL ${ }^{\mathrm{C} 82 \mathrm{~A}}$ (Supplementary Fig. 3). The non-interacting C-terminal region of GI (aa 920-1173; $\mathrm{GI}^{\mathrm{C}}$ ) failed in both assays (Supplementary Figs. 2, 3).

We next tested soluble in vitro purified $\mathrm{GI}^{\mathrm{N}}$ and $\mathrm{GI}^{\mathrm{C}}$ containing an N-terminal maltose-binding protein (MBP) tag to facilitate solubility and purification (Supplementary Fig. 4). To guard against the effects of co-purifying $E$. coli proteins, we determined the composition of each of the three bands by MALDI-TOF/TOF-MS. Only the appropriate regions of GI and MBP were identified (Supplementary Table 1).

$\mathrm{GI}^{\mathrm{N}}$ effectively prevents heat-denatured aggregation of $\mathrm{MDH}$ in vitro (Fig. 1). As the ratio of $\mathrm{GI}^{\mathrm{N}}$ to $\mathrm{MDH}$ was increased more $\mathrm{MDH}$ remained soluble and the proportion of heat-denatured 
a

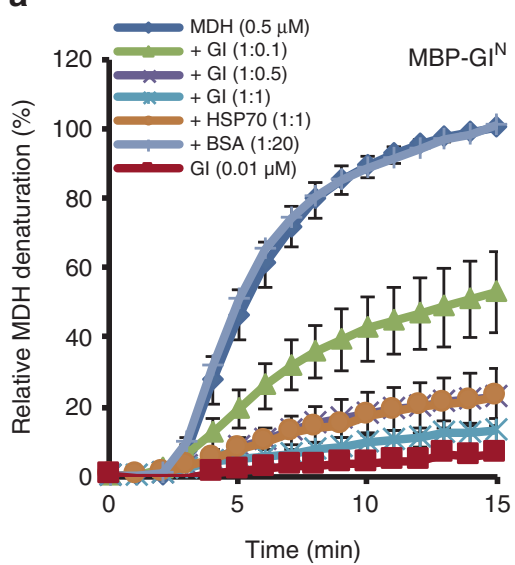

d

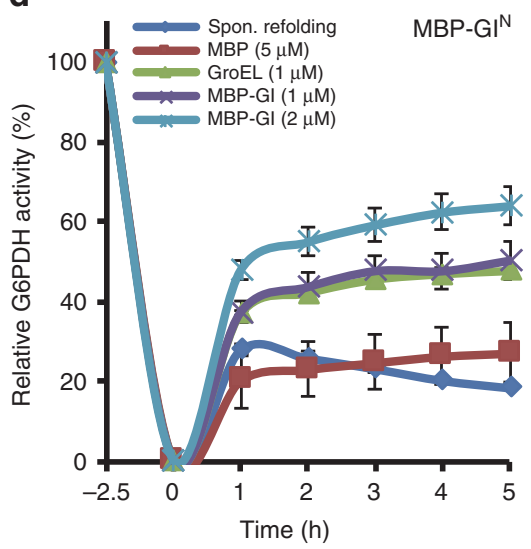

b

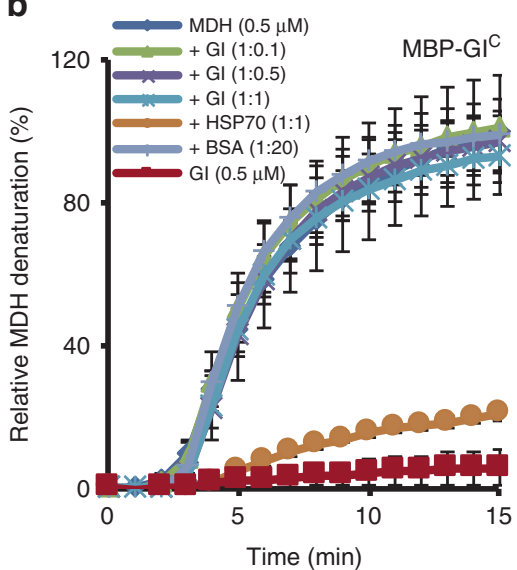

e

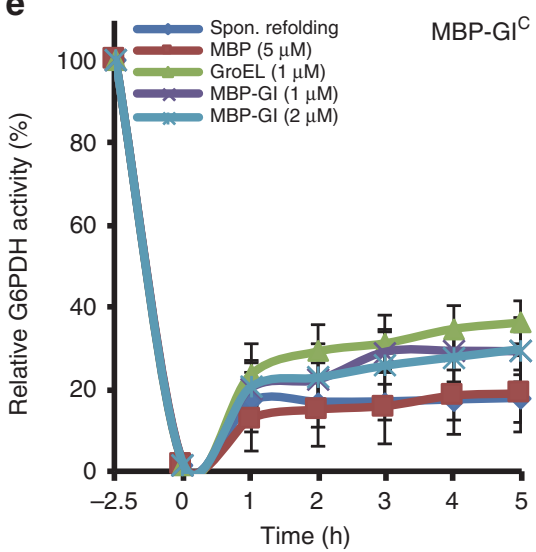

C

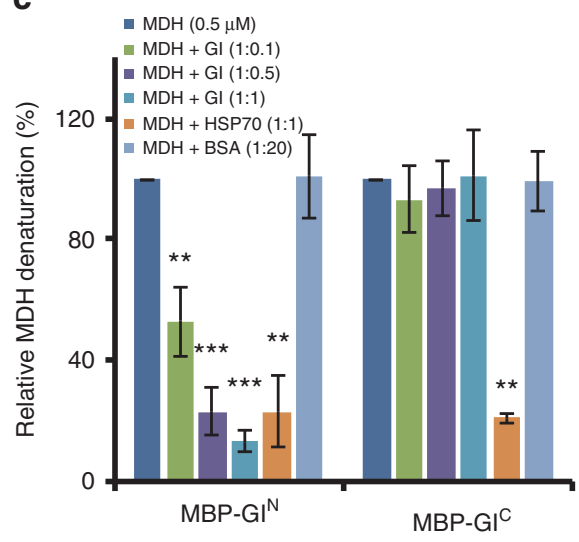

f

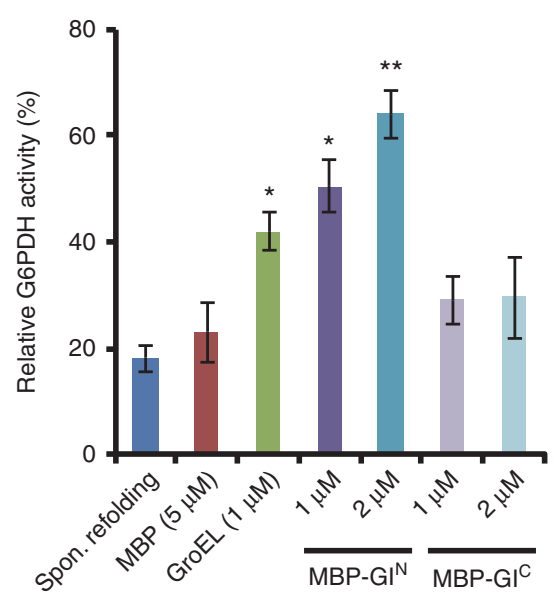

Fig. $1 \mathbf{~ G I}^{\mathbf{N}}$ exhibits general molecular chaperone activity in vitro. a MBP-GI ${ }^{\mathrm{N}}$ decreases heat-mediated MDH aggregation with increasing stoichiometric parity. b MBP-GI ${ }^{C}$ has no effect on heat-mediated MDH aggregation. Both Gl polypeptides were tested using MDH $(0.5 \mu M)$ as a model substrate under thermal denaturing conditions $\left(45^{\circ} \mathrm{C}\right.$ ) in various molar ratios. HSP70 and BSA used as positive and negative controls, respectively. c The mean MDH denaturation state at the treatment endpoint of $\mathbf{a}$ and $\mathbf{b}$ relative to thermal-denaturation of $\mathrm{MDH}$ alone. The holdase assay (a-c) measures the aggregation of the model substrate $\mathrm{MDH}(0.5 \mu \mathrm{M})$, by measuring the turbidity (light scattering) at $340 \mathrm{~nm}$ under thermal denaturing conditions for 15 min at $45^{\circ} \mathrm{C}$. The turbidity of $\mathrm{MDH}$ alone at $15 \mathrm{~min}$ was set to $100 \%$, and that from each treatment expressed relative to it. $\mathbf{d}$ MBP-GI ${ }^{\mathrm{N}}$ refolds chemically denatured G6PDH. e MBP-GI ${ }^{C}$ cannot refold chemically denatured G6PDH. $\mathbf{f}$ The mean G6PDH activity at the treatment endpoint of $\mathbf{d}$ and $\mathbf{e}$ relative to the activity of undenatured G6PDH. The foldase assay determines G6PDH activity by measuring absorbance at $340 \mathrm{~nm}$ (Abs 340 ) from NADPH formation. G6PDH was denatured in $4 \mathrm{M}$ guanidine $\mathrm{HCl}$ for $2.5 \mathrm{~h}(-2.5 \mathrm{~h}$ ), and the relative $\mathrm{G} 6 \mathrm{PDH}$ activity (compared to native G6PDH activity, set to $100 \%$ ) was monitored in the absence (Spon. Refolding, spontaneous refolding) or presence of MBP, GroEL, and MBP-GIN or MBP-GI ${ }^{C}$ for $5 \mathrm{~h}$ in renaturation buffer. GroEL and MBP were used as a positive and negative control, respectively. ${ }^{\star} P<0.05 ;{ }^{\star \star} P<0.01$; ${ }^{\star \star \star} P<0.001$; two-tailed Student's $t$-test. Data are means \pm s.e. ( $n=3$ )

$\mathrm{MDH}$ aggregates decreased, with $\mathrm{GI}^{\mathrm{N}}$ similarly effective as HSP70 at the same 1:1 MDH:chaperone ratio (Fig. 1a, c). The non-interacting C-terminal region of $\mathrm{GI}\left(\mathrm{GI}^{\mathrm{C}}\right.$ ) (Supplementary Figs. 2, 3) was ineffective at all stoichiometries (Fig. 1b, c). The MBP tag alone was not able to enhance the solubility of MDH (Supplementary Fig. 5) and BSA alone did not enhance aggregation (Supplementary Fig. 6). Similar results were obtained using His-GI ${ }^{\mathrm{N}}$ and His-GI ${ }^{\mathrm{C}}$ (Supplementary Fig. 7). These findings show $\mathrm{GI}^{\mathrm{N}}$ possesses general holdase activity.

We next asked whether GI can effectively aid in the refolding of a denatured substrate back into an enzymatically active state. Polypeptides with such abilities are referred to as possessing foldase activity ${ }^{35}$. Glucose 6-phosphate dehydrogenase (G6PDH) is often used as a model substrate for this test and G6PDH in vitro refolding can be facilitated by several chaperones ${ }^{36-38}$. Chemically denatured G6PDH was tested for the return of enzyme activity in the presence of $\mathrm{GI}^{\mathrm{N}}$, the MBP tag alone, GroEL (positive control) or buffer alone. The bacterial protein GroEL is a well-studied paradigm of the chaperonin class of molecular chaperones and has been used previously as a positive control for foldase activity ${ }^{39,40} . \mathrm{GI}^{\mathrm{N}}$ equaled or exceeded the ability of GroEL to renature G6PDH to a level three times higher than that achieved by spontaneous renaturation, while $\mathrm{GI}^{\mathrm{C}}$ was ineffective (Fig. 1d-f). Taken together, these results demonstrate an inherent chaperone activity for $\mathrm{GI}^{\mathrm{N}}$.

ZTL is a client of a GI/HSP90 chaperone complex in vitro. We next determined whether ZTL is a specific client of $\mathrm{GI}^{\mathrm{N}}$ in vitro. We performed holdase experiments using wild-type ZTL $\left(\mathrm{ZTL}^{\mathrm{WT}}\right)$ and the $\mathrm{C} 82 \mathrm{~A}$ variant $\left(\mathrm{ZTL}^{\mathrm{C} 82 \mathrm{~A}}\right)$ that eliminates photochemical activity and significantly reduces GI/ZTL interactability in planta 9 . At a $1: 1$ stoichiometry $\mathrm{GI}^{\mathrm{N}}$ reduces $\mathrm{ZTL}^{\mathrm{WT}}$ aggregation by $50 \%$ and at a $1: 3 \mathrm{ZTL}^{\mathrm{G}} \mathrm{GI}^{\mathrm{N}}$ ratio $\mathrm{ZTL}^{\mathrm{WT}}$ remains 
a

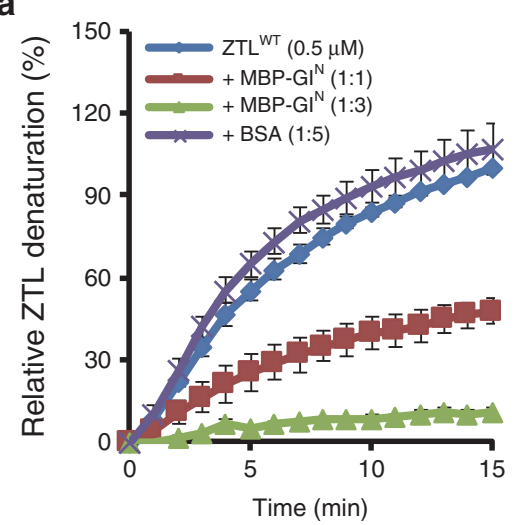

d

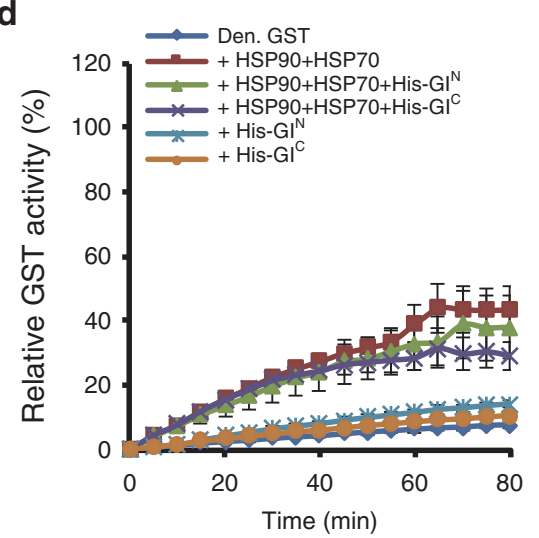

b

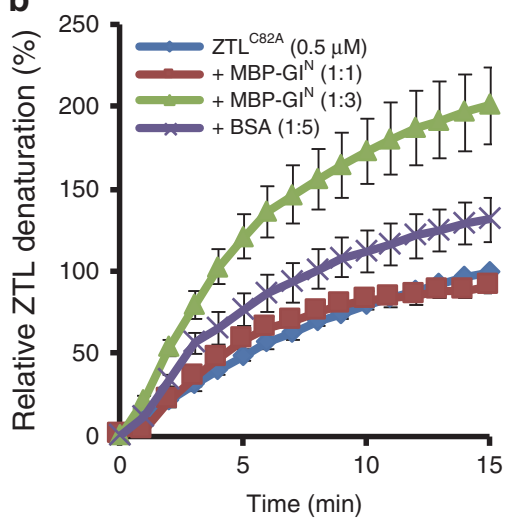

e

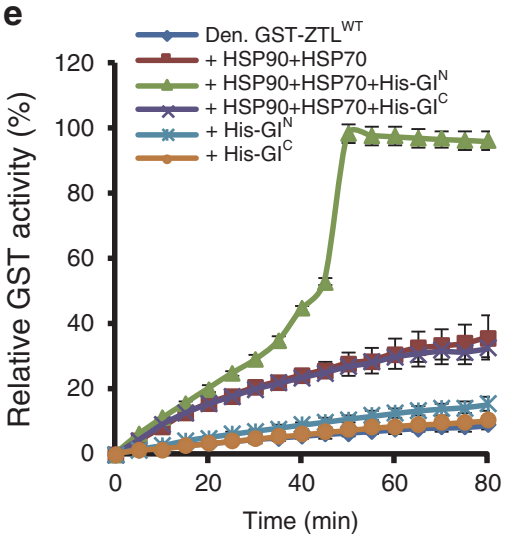

C

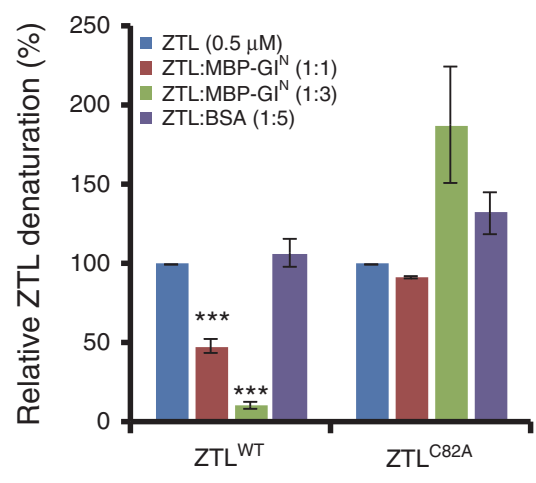

f

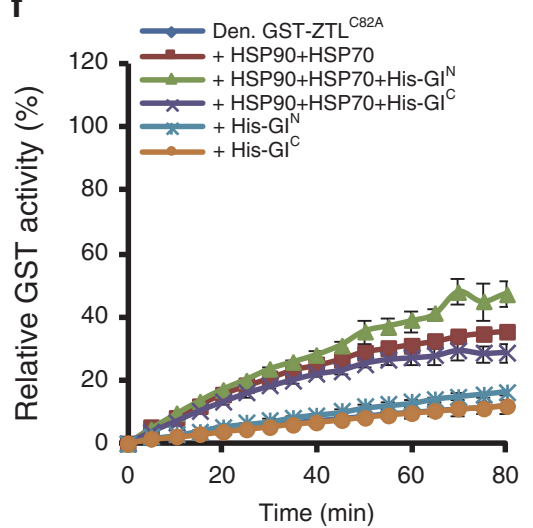

g

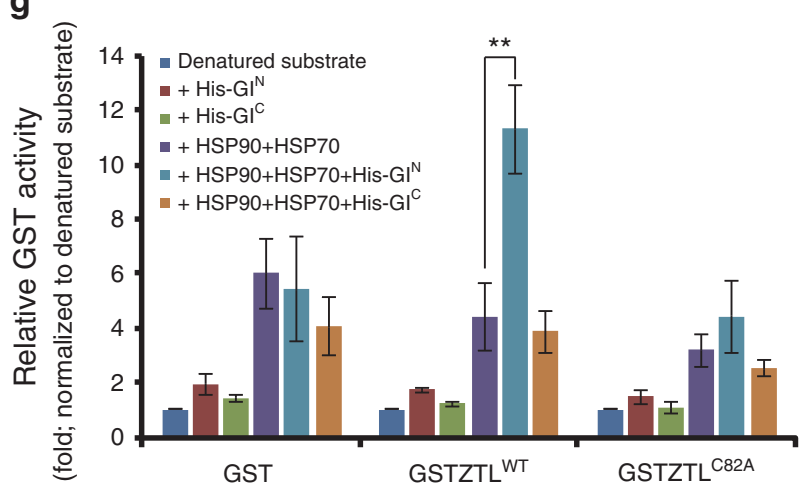

Fig. 2 ZTL is a specific client of $\mathbf{~ G I}^{\mathbf{N}}$ chaperone activity in vitro. a MBP-GIN decreases heat-mediated ZTLWT aggregation with increasing levels of $\mathrm{MBP}-\mathrm{GI}{ }^{\mathrm{N}}$. $\mathbf{b} \mathrm{MBP}-\mathrm{GI}{ }^{\mathrm{N}}$ has no effect or increases heat-mediated aggregation of the ZTL ${ }^{\mathrm{C} 82 \mathrm{~A}}$ allele. $\mathbf{c}$ The mean denaturation state at the treatment endpoint of $\mathbf{a}$ and $\mathbf{b}$ relative to thermal-denaturation of $\mathrm{ZTL}{ }^{\mathrm{WT}}$ or $\mathrm{ZTL}{ }^{\mathrm{C} 82 \mathrm{~A}}$ alone. BSA used as a non-specific protein control. Holdase activity of $\mathrm{MBP}-\mathrm{Gl}{ }^{\mathrm{N}}$ was measured as the change in turbidity at $340 \mathrm{~nm}$ (aggregation of $Z \mathrm{TL}^{\mathrm{WT}}$ or $Z \mathrm{ZL}^{\mathrm{C} 82 \mathrm{~A}}(0.5 \mu \mathrm{M})$ ) under thermal denaturing conditions $\left(45^{\circ} \mathrm{C}\right)$ for 15 min. The value of $Z T L L^{W T}$ or $Z T_{L}{ }^{C 82 A}$ alone at $15 \mathrm{~min}$ was set to $100 \%$, and turbidity at $340 \mathrm{~nm}$ from each treatment expressed relative to it. BSA used as a nonspecific protein control. d-f Gl acts synergistically with HSP90 and HSP70 to reactivate denatured GST-ZTL. d GST, e GST-ZTLWT, and f GST-ZTL ${ }^{\text {C82A }}$ were heat-denatured at $45^{\circ} \mathrm{C}$ and immediately mixed with His-GIN $(0.05 \mu \mathrm{M})$ or His-GI $(0.05 \mu \mathrm{M})$ in the absence or presence of $\mathrm{HSP} 90(0.1 \mu \mathrm{M})$ and HSP70 $(0.5 \mu \mathrm{M})$. Enzyme activity of undenatured GST, GST-ZTLWT, and GST-ZTL ${ }^{\mathrm{C} 82 \mathrm{~A}}$ was set to $100 \%$ for $\mathbf{d}$, e and $\mathbf{f}$, respectively. $\mathbf{g}$ Mean GST activity at the treatment endpoint of $\mathbf{d}-\mathbf{f}$ was normalized to the spontaneously refolding value of denatured GST or GST-fusions set to 1 . The foldase assay determined GST activity by measuring the formation of a GS-DNB conjugate (GST reaction product) as determined by absorbance at $340 \mathrm{~nm}\left(\right.$ Abs 340 ). ${ }^{\star \star} P<0.01$; ${ }^{\star \star \star} P<0.001$; two-tailed Student's $t$-test. Data are means \pm s.e. $(n=3)$

fully soluble (Fig. 2a, c). In contrast, $\mathrm{GI}^{\mathrm{N}}$ is unable to prevent $\mathrm{ZTL}^{\mathrm{C} 82 \mathrm{~A}}$ denaturation even at higher $\mathrm{GI}^{\mathrm{N}}$ concentrations (Fig. 2b, c). These results show that a specific interaction with ZTL is required for $\mathrm{GI}^{\mathrm{N}}$ holdase function.

To determine if $\mathrm{GI}^{\mathrm{N}}$ can specifically refold ZTL in vitro we used a glutathione S-transferase (GST)-ZTL fusion protein and observed the ability of $\mathrm{GI}^{\mathrm{N}}$ to restore GST activity after heat denaturation. As an F-box protein that is part of a much larger SCF (Skip1/Cullin/F-box) complex, ZTL does not have an inherent enzyme activity that can be assayed to assess proper refolding. Given that a specific GI-ZTL interaction is needed for holdase activity (Fig. $2 \mathrm{a}-\mathrm{c}$ ), we reasoned that $\mathrm{GI}^{\mathrm{N}}$-dependent restoration of GST enzyme activity to denatured GST-ZTL would reflect the restoration of ZTL to its native configuration. We used 
the artificial substrate 1-chloro-2,4-dinitrobenzene (CDNB) to fluorometrically assess GST activity ${ }^{41,42}$. In these experiments, we also included HSP90 and HSP70, based on our earlier findings that implicate HSP90 in ZTL maturation ${ }^{32}$ and the co-elution of HSP90, ZTL, and GI as large protein complexes in planta (Supplementary Fig. 8c, d). Additionally, HSP70 often acts together with HSP90 as an early step in an HSP70/HSP90 chaperoning cascade ${ }^{43}$. Using denatured GST alone as a negative control, we found that a mixture of HSP90 + HSP70 can restore ca. $40 \%$ of GST activity, while $\mathrm{GI}^{\mathrm{N}}$ and $\mathrm{GI}^{\mathrm{C}}$ alone are ineffective. Inclusion of $\mathrm{GI}^{\mathrm{N}}$ or $\mathrm{GI}^{\mathrm{C}}$ to the HSP70/HSP90 mixture does not enhance this effect (Fig. 2d, g). In contrast, the enzyme activity of denatured GST-ZTL is completely restored when $\mathrm{GI}^{\mathrm{N}}$ is included in the assay mixture with HSP90 + HSP70, while $\mathrm{GI}^{\mathrm{C}}$ has no such synergistic effect (Fig. 2e, g). Importantly, when GST-ZTL ${ }^{\mathrm{C} 22 \mathrm{~A}}$ is used under the same conditions no significant increase in GST activity is observed (Fig. 2f). These results indicate that a specific interaction between $\mathrm{ZTL}^{\mathrm{WT}}$ and $\mathrm{GI}^{\mathrm{N}}$ is necessary for the full restoration of GST activity in GST-ZTL and that $\mathrm{GI}^{\mathrm{N}}$ acts synergistically with HSP90 and HSP70. This indicates that in vitro GI can act as a co-chaperone with HSP90/HSP70 in the maturation of fully functional ZTL.

GI is necessary for full maturation of ZTL activity in vivo. We further extended these studies in transgenic Arabidopsis by assessing the effectiveness of ZTL-luciferase (35S:ZTL-LUC) translational fusion enzyme activity in WT and $g i$ mutant backgrounds. Luciferase enzyme activity has been used widely for measuring the status of proper protein folding both in vitro and in vivo ${ }^{44-46}$. We reasoned that a measure of properly folded/matured ZTL protein could come from observing the ratio of ZTL-LUC luciferase activity (by luminometry) to the level of ZTL-LUC protein levels (by immunoblotting), which we term ZTL-LUC-specific activity.

We first validated that the ZTL-LUC fusion protein recapitulates features of endogenous ZTL in planta in three ways. Endogenous ZTL oscillates with peak expression at ZT13 and lowest levels at ZT1 in light/dark cycles ${ }^{9}$. We determined that ZTL-LUC protein similarly oscillates by measuring protein levels at both time points, validating that this fusion protein is post-transcriptionally regulated as endogenous ZTL (Supplementary Fig. 9a, lanes 1 and 2). Importantly, ZTL-LUC level is constitutively diminished in gi-201 relative to WT, consistent with a low level of endogenous ZTL protein in $g i$ mutants ${ }^{9}$ (Supplementary Fig. 9a, lanes 3 and 4). These tests showed that ZTL-LUC protein is diurnally regulated and requires GI for accumulation. We next tested the ability of ZTL-LUC to interact with GI in planta by transient co-expression in N. benthamiana. ZTL $^{\text {WT }}$-LUC successfully co-immunoprecipitated with GI-HA (Supplementary Fig. 9b, lane 3), while a poorly interacting allele of ZTL (ZTL ${ }^{\mathrm{G} 46 \mathrm{E}}$; failed (ZTL ${ }^{\mathrm{G} 46 \mathrm{E}}$-LUC; Supplementary Fig. 9b, lane 4), demonstrating interaction specificity between GI and ZTL-LUC. Third, we tested the ability of ZTL-LUC to reduce levels of the known SCF ${ }^{\mathrm{ZTL}}$ substrates, TOC1, and PRR5 $5^{5-7}$. Coexpression of ZTL with TOC1 or PRR5 significantly reduces the levels of the two substrate proteins when compared to their coexpression with LUC (Supplementary Fig. 9c; compare GFP-PRRn panels, lanes 1 and 3; 4 and 6), but not that of the non-SCF ${ }^{Z T L}$ target, $\mathrm{PRR7}^{7}$ (Supplementary Fig. 9c; compare GFP-PRRn panel, lanes 7 and 9). Co-expression of ZTL ${ }^{\mathrm{WT}}$-LUC with TOC1 or PRR5 is very similar to authentic ZTL in reducing their levels, when the expression level of the two ZTL proteins is taken into account (Supplementary Fig. 9c; compare GFP-PRRn panels, lanes 2 and 3; 5 and 6). In contrast neither ZTL-LUC nor authentic ZTL has an effect on PRR7 (Supplementary Fig. 9c; compare GFP-PRRn panel, lanes 8 and 9). Taken together these
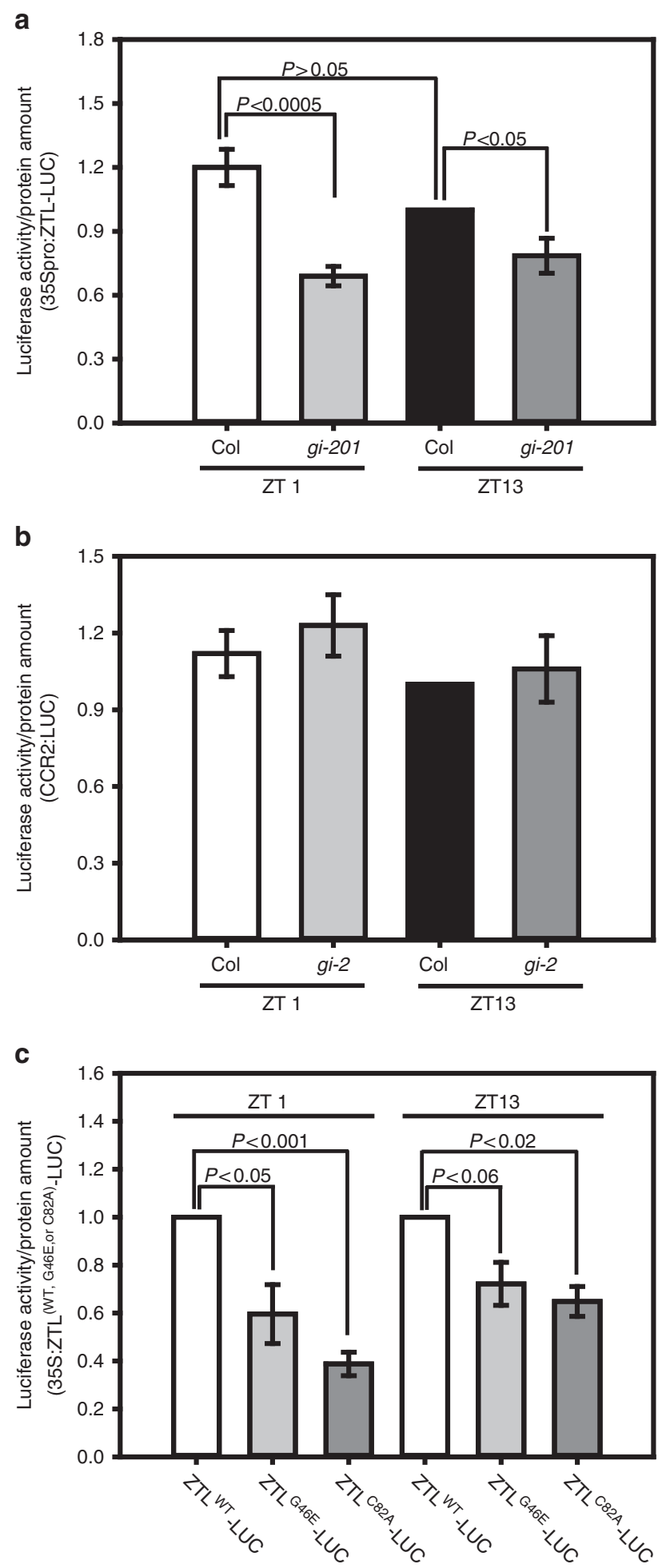

Fig. $\mathbf{3}$ GI is required in vivo for complete ZTL activity. a Relative-specific activity of ZTL-LUC at ZT1 and ZT13 in the Col and gi-201 background. b Relative-specific activity of LUC from the CCRZ:LUC transgene in the Col

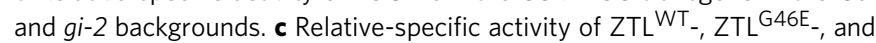
ZTL ${ }^{C 82 A}$-LUC at ZT1 and ZT13 in the Col background. a-c Specific activity was determined by the ratio of luminescence (enzyme activity) to LUC protein levels derived from ZTL ${ }^{W T} T_{-}, Z_{T L}{ }^{G 46 E_{-}}, Z_{T L}{ }^{C 82 A}-L U C$ or LUC protein alone. See "Methods" for details. Data are means \pm s.e. of eight (a) or four (b, c) independent samples 
results indicate that the post-translational regulation of ZTL-LUC recapitulates that of authentic ZTL and possesses a similar ability to mediate TOC1 and PRR5 turnover.
We next compared the ratio of ZTL-LUC luciferase activity per ZTL-LUC protein amount in WT and gi-201 and observed that the specific activity of ZTL-LUC is significantly lower in gi-201,

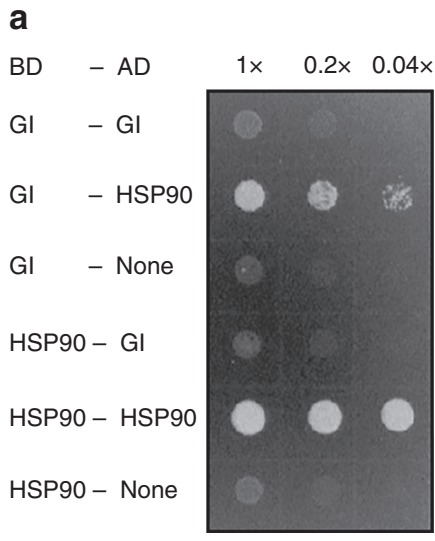

b

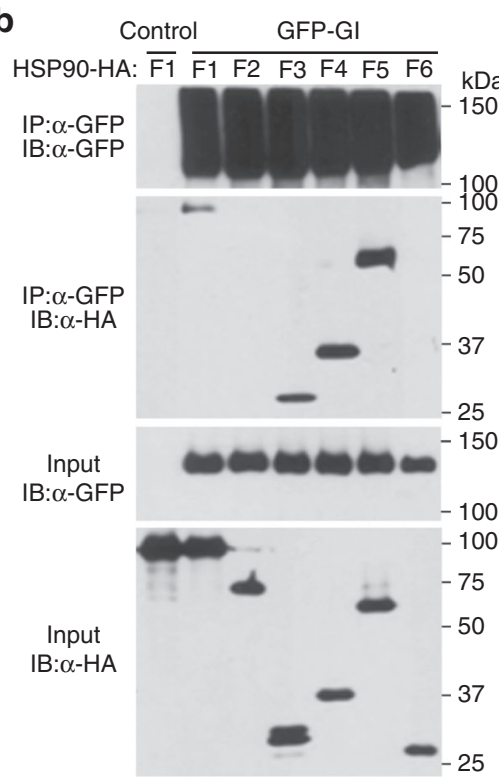

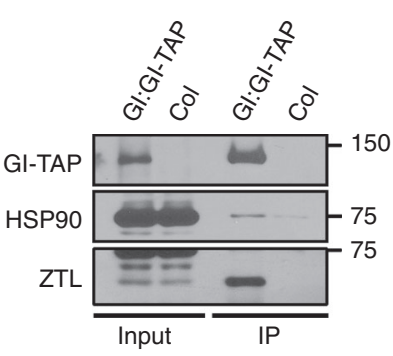

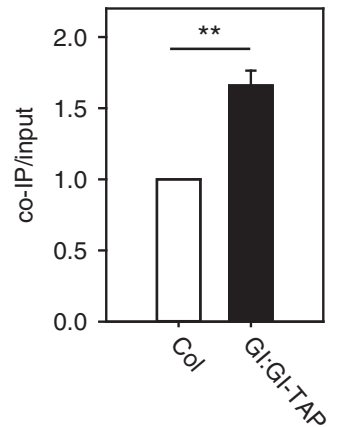

Genotype
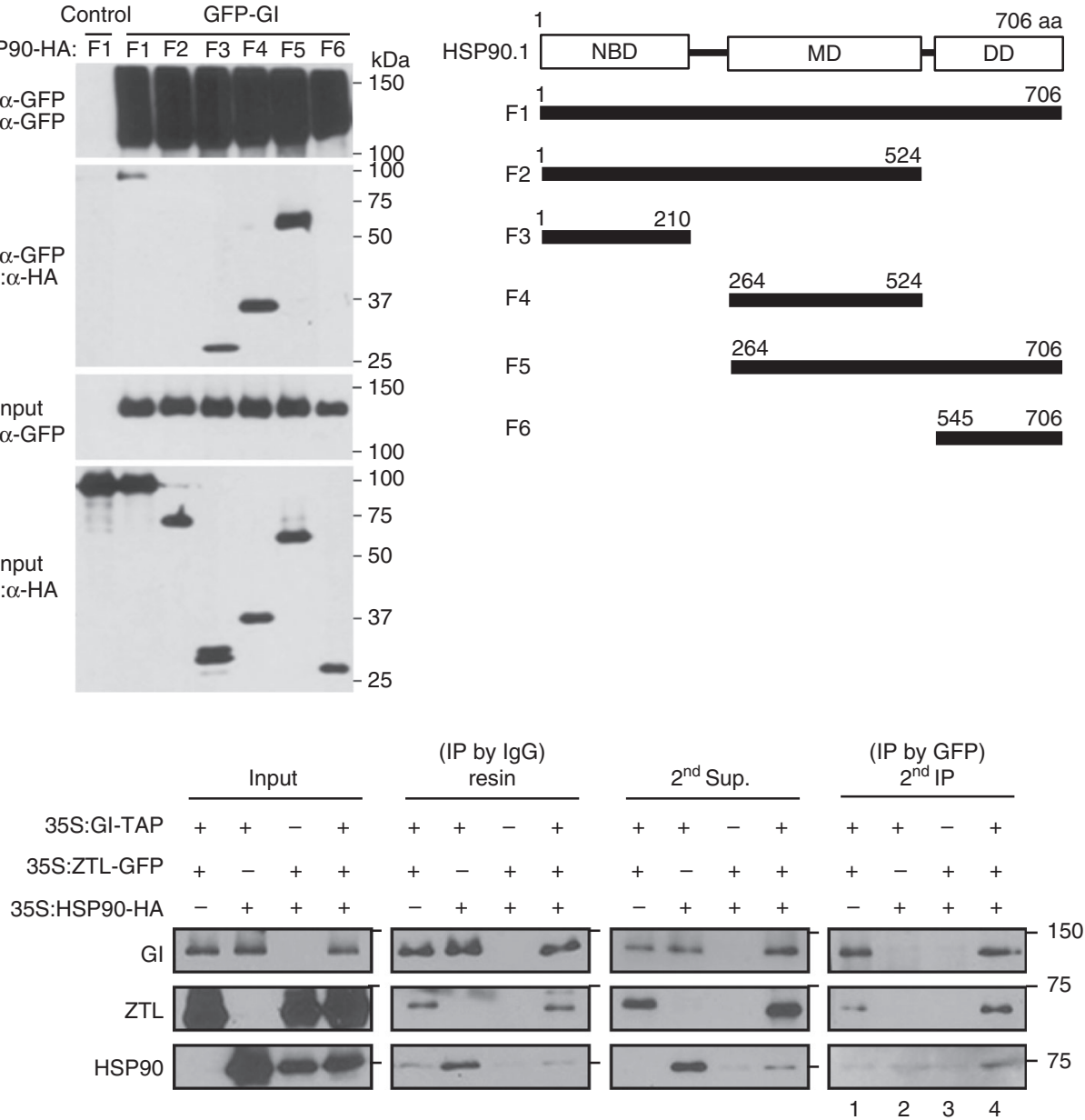

Fig. 4 GI complex formation with ZTL and HSP90 in vivo. a GI and HSP9O interact directly in yeast (left panel) and in planta (right panel). Full-length GI and HSP9O protein interaction via yeast two-hybrid was determined by growth on leucine deficient media. Transgenic Arabidopsis expressing Gl:GI-TAP immunoprecipitates with endogenous HSP9O and ZTL (right panels). Untransformed Col controlled for non-specific HSP90 interaction. Quantification of HSP90 in GI-TAP immunoprecipitations (IPs) (far right panel; mean \pm s.e.m.; $\left.{ }^{\star \star P}<0.01\right)(n=4)$. b HSP90 deletion interactions with GI. Agrobacteria harboring GI-GFP or HSP90 and its respective deletions tagged with $3 \times \mathrm{HA}$ were co-infiltrated into N. benthamiana leaves. Anti-GFP (IP) were followed by detection of co-immunoprecipitated HSP90-HA and respective deletions. Representative of three trials with similar results. Right panel: HSP90 domain structure and respective deletion scheme. IP immunoprecipitating antibody, IB immunoblot antibody, NBD nucleotide-binding domain, MD middle domain, DD dimerization domain. c GI, ZTL, and HSP90 form a tripartite protein complex in planta. Sequential co-immunopreciptations used GI-TAP in the primary IP followed by IP of ZTL-GFP (anti-GFP ab) from the protease-released supernatant (2nd Sup.). The final detection of HSP90-HA (anti HA ab) in lane 4 indicates HSP90-HA associated with ZTL-GFP from the first IP. N. benthamiana leaves were triply co-infiltrated with 35S:GI-TAP/35S:HSP90-HA/35S:ZTLGFP simultaneously or in all pairwise combinations. Representative of three independent trials 
relative to $\mathrm{WT}$, at both the minimum (ZT1) and maximum (ZT13) levels of ZTL expression (Fig. 3a; Supplementary Fig. 10a-d). In the WT, ZTL-LUC specific activity was similar at both ZT1 and ZT13. In gi-201, ZTL-LUC-specific activity, while consistently lower than WT, was also similar at both time points, indicating that GI is required throughout the circadian cycle to effect fully functional ZTL. Luciferase alone (CCR2pro-LUC) expressed in WT and gi backgrounds with similar evening phasing as ZTL showed no difference in the level of LUC-specific activity at either time point tested (Fig. 3b).

Additionally, we tested ZTL-LUC-specific activity for ZTL ${ }^{\text {82A }}$-LUC and ZTL ${ }^{\text {G46E }}$-LUC variants expressing in the WT GI background (Col). As these variants interact poorly with $\mathrm{GI}^{9}$ we reasoned that the respective ZTL ${ }^{\text {mut }}$-LUC specific activity would be diminished if GI is needed for maturation. For both ZTL variants at both time points, the variant-specific activity was significantly reduced relative to WT (Fig. 3c; Supplementary Fig. 11). Taken together, results from both in vivo approaches indicate that GI is required for the maturation of fully active ZTL, consistent with the in vitro results (Fig. 2).

GI forms a ternary complex with HSP90 and ZTL in planta. GI can form tetramers in vitro ${ }^{47}$ so we further tested whether GI occurs in large in vivo complexes in Arabidopsis. In non-reducing gels, large GI-containing complexes are detectable and are more enriched in blue (B) and constant white light (LL) than in darkness (D) and red light (R) (Supplementary Fig. 13), consistent with our previous findings 9 . This light-dependent formation of multimeric forms of GI suggests it might function in the context of large complexes in vivo.

The synergistic effect of GI and HSP90 + HSP70 in vitro (Fig. 2e, g) and the co-elution of GI, HSP90, and ZTL during gel filtration (Supplementary Fig. 8) led us to further investigate the composition of the in vivo complexes. HSP90 is a homodimer comprising three well-defined functionally distinct domains that are evolutionarily highly conserved ${ }^{48}$. The $\mathrm{N}$-terminal nucleotidebinding domain (NBD) contains the ATP-binding and hydrolysis region, the middle domain (MD) also participates in ATP hydrolysis, and the C-terminal domain contains the dimerization domain (DD) region ${ }^{48,49}$. Client protein and co-chaperone binding to HSP90 may occur via any of these domains ${ }^{43,50,51}$

Yeast two-hybrid tests show that full-length GI and HSP90 interact (Fig. 4a). We then tested discrete domain deletions of HSP90 and full-length GI in transient expression assays (Fig. 4b). We detected especially strong co-immunoprecipitation (co-IP) of HSP90 polypeptides when the MD was present either alone or with the HSP90 DD, except when the NBD was also present (Fig. 4b). Since the NBD alone also bound GI it appears that the conformation of an NBD + MD polypeptide blocks GI access. (Fig. 4b). Similarly, an N-terminal portion of $\mathrm{GI}^{\mathrm{NT}}$ (aa 1-391) also selectively and strongly co-immunoprecipitated with middledomain containing regions of HSP90, but much more weakly with polypeptides where the NBD is present (Supplementary Fig. 14). Since HSP90 conformation changes with the N-terminal binding of ATP ${ }^{51,52}$, it is possible that a GI-HSP90 interaction is modulated by ATP binding/hydrolysis.

In plants expressing GI:GI-TAP both ZTL and HSP90 can be co-immunoprecipitated (Fig. 4a). To establish that all three proteins can exist within one complex we performed sequential co-immunoprecipitations using GI-TAP in the primary IP followed by an IP of ZTL-GFP and detection of HSP90-HA in the final $\left(2^{\text {nd }}\right)$ IP. The presence of enriched levels of HSP90 in the 2nd IP (Fig. 4c, lane 4; Supplementary Fig. 12) is only possible if HSP90 is associated with the ZTL-GFP that was initially complexed with GI-TAP. These results show the presence of a

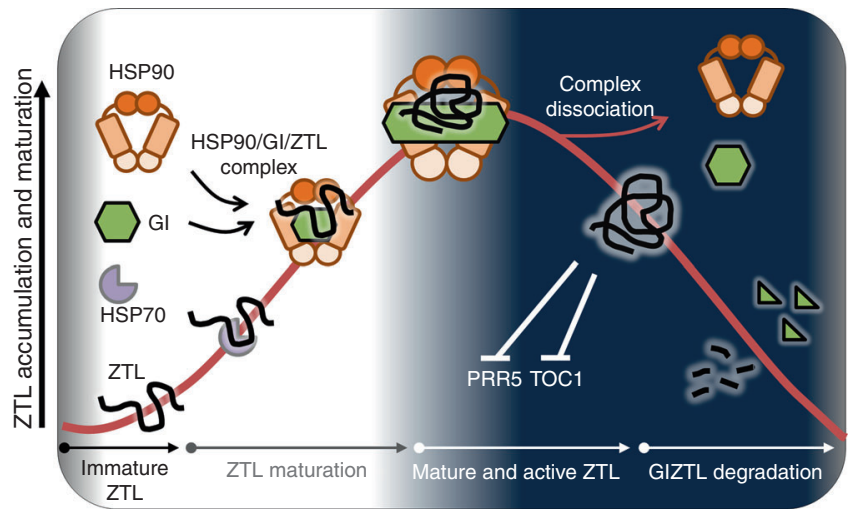

Fig. 5 Post-transcriptional oscillation of ZTL is regulated by $\mathbf{G I}$ and HSP90. Nascent ZTL may be first captured by HSP7O in an early complex, and then transferred to a second complex comprising HSP9O and the co-chaperone GI. Order of ZTL interaction with GI and HSP9O is unknown. GI oligomerization and ZTL interaction is enhanced in the light, which may increase the binding capacity with ZTL and HSP90. Matured/active ZTL dissociates from the complex, to form SCF ${ }^{Z T L}$ which ubiquitylates PRR5 and TOC1. During the dark period ZTL is degraded together with GI

ternary complex in planta, supporting the gel filtration (Supplementary Fig. 8) and synergistic in vitro folding results (Fig. 2g). Taken together, these findings indicate that GI acts as a co-chaperone with HSP90 to mature ZTL into its fully functional form (Fig. 5).

\section{Discussion}

Proteostasis is the sum total of processes involving the synthesis, folding, and maturation, and turnover of polypeptides in the cell. Molecular chaperones are essential in cellular proteostasis, primarily in promoting and regulating the correct folding and maturation of their client proteins ${ }^{27}$. HSP90 is one of the most ubiquitous chaperones in eukaryotes, playing a central role in all aspects of cell regulation ${ }^{49,53,54}$. The extremely wide-range of HSP90 clients requires mechanisms to determine client specificity and this is achieved, in part, through the complexing of particular co-chaperones and other adaptors with HSP90 31,50 .

Our previous study established ZTL as a client of HSP90 but the question of specificity was unresolved ${ }^{32}$. Here we have identified GI as a co-chaperone that interacts with HSP90 to specify ZTL as a client of the larger complex. HSP90 and HSP70 together can restore $35 \%$ of the enzyme activity of denatured ZTL-GST but the inclusion of $\mathrm{GI}^{\mathrm{N}}$, representing more than $70 \%$ of the fulllength polypeptide, synergistically restores ZTL-GST to $100 \%$ activity (Fig. 2e). Mutant ZTL-GST (ZTL ${ }^{\mathrm{C} 82 \mathrm{~A}}$ ), which greatly diminishes the ZTL-GI interaction, also renatures to only ca. 35\% activity in the presence of HSP70/HSP90 alone, but addition of $\mathrm{GI}^{\mathrm{N}}$ has little effect (Fig. 2f).

Additionally, the inability of GI alone to substantially restore ZTL-GST activity without HSP90/HSP70 suggests it may act primarily as a holdase to position ZTL correctly in the presence of HSP90. The existence of a ZTL-GI-HSP90 complex in vivo (Fig. 4c) supports this notion. We suggest that GI facilitates steps after the HSP70-to-HSP90 shuttling of the client. HSP70 typically acts early in the folding process, by binding to short, five-residue long hydrophobic stretches of amino acids of the client ${ }^{43}$. This complex then hands off the nascently folded client substrate to HSP90 for final conformational maturation and stabilization (Fig. 5).

The strong, synergistic promotion of ZTL-GST to full activity through the addition of $\mathrm{GI}^{\mathrm{N}}$ to an HSP70/HSP90 complex is similar to previous reports of the enhancement of chaperone 
activity (e.g., HSP90) when co-chaperones are included in the reaction ${ }^{55-57}$. This may occur through a change in the inherent ATPase activity of HSP90, by helping direct HSP90 to specific client proteins or through unknown mechanisms. In vivo, ZTL-LUC-specific activity was reduced either in the absence of GI (Fig. 3a) or when interaction with GI was diminished by ZTL mutation (Fig. 3c). This, too, is consistent with increased recruitment of clients to HSP90 by co-chaperones. Because ZTL protein abundance tracks GI levels so closely ${ }^{9}$ it is likely that the oscillation in GI protein accumulation is the determinant in ZTL maturation. As well, the specific activity of ZTL-LUC is very similar in the WT at both ZT1 and ZT13 (Fig. 3a), when the ZTL and GI levels are both near their lowest (ZT1) and highest (ZT13) levels. This also supports the notion that GI levels control the extent of ZTL maturation, such that in the absence of GI ZTL maturation still occurs but at a slower, less efficient rate.

The entry point of known co-chaperones to the HSP90 chaperone cycle can vary greatly. For example, the mammalian co-chaperone Hop connects HSP90 and HSP70 in a multichaperone complex, where it facilitates the transfer of client proteins from an early HSP70 complex (HSP70-HSP40) to an intermediate complex (HSP70-HSP90) ${ }^{48}$. Like Hop, other co-chaperones such as CDC37, and SGT1 and RAR1 in plants, also act to deliver the client to HSP90, often slowing the rate of ATPase activity inherent in HSP90 action ${ }^{50,52,58,59}$. Other co-chaperones (e.g., Sba1/p23; Aha1) act later in the maturation process and are not explicitly involved in client delivery to the HSP90 complex ${ }^{50,52}$. Further work is necessary to determine the precise point of GI entry to the HSP90 chaperone cycle, but our findings support participation in an early step where GI may either first bind ZTL for proper HSP90 access or co-bind ZTL with HSP90.

Different co-chaperones bind to different portions of HSP90 and no conserved co-chaperone-binding domain has been identified ${ }^{51}$. This is consistent with the different interaction regions of GI and HSP90 identified in the coimmunoprecipitation interaction tests (Fig. 4b; Supplementary Fig. 14). The MD domain of HSP90 is needed to interact with full-length GI and the GI N-terminus, but the interaction is greatly weakened when the N-terminal NBD is present. Since HSP90 conformation changes with the N-terminal binding of ATP $^{51,52}$, it is possible that a GI-HSP90 interaction is modulated by ATP binding/hydrolysis.

We have now identified a mechanism that can explain the far-reaching effects of GI on plant physiology, metabolism, and development. Given the diversity of phenotypes observed in $g i$ mutants ${ }^{15}$, GI is likely to effect the maturation of a wide range of client proteins. This role could be similar to that of yeast co-chaperone $\mathrm{p} 23$, which acts together with, and separately from, HSP90 in a wide-ranging global network of chaperone activity $^{60,61}$. It is also likely that additional factors complex with GI, separately or together with HSP90, to confer specificity to the roles GI has in plant biology. Additionally, the strong diel and circadian oscillations in GI levels $s^{9,18,23}$ now implicate the circadian clock in a chaperone surveillance system that helps to globally regulate proteostasis in vascular plants.

\section{Methods}

Plasmid construction and plant materials. The constructs of full-length ZTL (WT), ZTL(G46E), and ZTL(C82A) fused with LUC were prepared using the Gateway system (Invitrogen). Entry clones for ZTL, ZTL(G46E), ZTL(C82A) fused with LUC were generated by transferring the ZTL-LUC fragment, from the plasmids generated by recombination reaction of ZTL(WT), ZTL(G46E), and ZTL (C82A) entry clones with the Gateway version of pOmegaLUC_SK+, into the pCR-CCD-F vector ${ }^{22,62}$. The final constructs for the generation of Arabidopsis transgenic plants were established by the LR recombinase reaction using each entry clone and pMDC $32^{63}$. A $35 S: Z T L(W T)-L U C$ transgenic line expressing stable ZTL-
LUC transcript levels when crossed with gi-201 was selected. 35S:ZTL(G46E)-LUC and 35S:ZTL(G46E)-LUC transgenic lines were chosen, based on their comparable expression of ZTL-LUC to that in 35S:ZTL(WT)-LUC. GI:GI-TAP and GI:GI-HA ${ }^{23}$ $C C R 2-L U C+$ and $g i-2 C C R 2-L U C+{ }^{64}$ have been described previously. The GFP-GI and GFP-GI ${ }^{\mathrm{NT}}$ constructs were generated by LR recombination with pENTR2BGI, pENTR2B-GI NT, and pMDC45-GFP binary vector, respectively. Supplementary Table 2 lists primers used in construction of these plasmids and those in the following sections.

Recombinant protein expression. cDNA of GI ${ }^{\mathrm{N}}\left(1-858\right.$ aa) and GI ${ }^{\mathrm{C}}(920-1173$ aa) were cloned into the donor vector (pDONR-zero) and subsequently moved into the gMAL $\mathrm{c} 2 \mathrm{~B}$ and gRSETA vector to produce recombinant protein with an $\mathrm{N}$-terminal maltose-binding protein (MBP-) and 6xHis tag (His-), respectively, using the recombination-based Gateway cloning system (Invitrogen), according to the manufacturer's instructions. Site-directed mutagenesis for MBP-ZTLC82A and GST-ZTL ${ }^{\text {C2A }}$ were generated using pMalc2X::ZTL (for MBP-ZTL $\left.{ }^{\text {WT }}\right)^{32}$ and pGEX-KG::ZTL (GST-ZTL ${ }^{\mathrm{WT}}$ ) ${ }^{65}$ as a template for Pfu Turbo DNA polymerase (QuickChange Site-Dircted Mutagenesis Kit; Stratagene), according to the manufacturer's instructions. The pET28a::HSP90.2 (His-HSP90), pMalc2X::ZTL (MBP-ZTL), and pET41a::HSP70 (GST-HSP70) were prepared as described previously $^{32,66}$. The plasmids without $p M A L c 2 X$ (for produce MBP fusion protein only), pGEX5X-1 (for GST only), pET28a::HSP90.2 (At5G56030), and pMalc2X:: ZTL were transformed into E. coli BL21 (DE3) pLysS for recombinant protein expression. The E. coli transformants were grown at $37^{\circ} \mathrm{C}(\mathrm{OD} 600=0.8)$ and His-HSP90 $0^{32}$ and GST-HSP70 (EU541356) ${ }^{66}$ were induced by $0.5 \mathrm{mM}$ isoprophyl1-thio- $\beta$ - $\mathrm{D}^{- \text {galactopyranoside (IPTG) and MBP, MBP-GI }}{ }^{\mathrm{N}}, \mathrm{MBP}-\mathrm{GI}^{\mathrm{C}}$, His-GI ${ }^{\mathrm{N}}$, His-GIC, MBP-ZTL WT, MBP-ZTL ${ }^{\mathrm{C} 2 \mathrm{~A}}$, GST, GST-ZTL ${ }^{\mathrm{WT}}$, and

GST-ZTL ${ }^{\mathrm{C} 2 \mathrm{~A}}$ by $1 \mathrm{mM}$ IPTG. After $3 \mathrm{~h}$ at $30^{\circ} \mathrm{C}$ cultures were harvested, resuspended in $1 \times$ PBS and incubated for $20 \mathrm{~min}$ in the presence of $1 \%(\mathrm{v} / \mathrm{v})$ Triton $\mathrm{X}-100$ followed by disruption by sonication. For GST-ZTL ${ }^{\mathrm{WT}}$ and GST-ZTL ${ }^{\mathrm{C} 2 \mathrm{~A}}$, cells were incubated in $1 \%(\mathrm{v} / \mathrm{v})$ of sodium lauroyl sarcosinate (sarkosyl) followed by incubation in $1 \%(\mathrm{v} / \mathrm{v})$ Triton X-100 before disruption by sonication ${ }^{42}$. After centrifugation, supernatants of His-tagged proteins were loaded onto a Ni-NTA Sepharose CL-6B affinity column (Peptron), those of GST-fusion proteins onto a Glutathione Sepharose 4B Fast Flow (GE healthcare), and MBP-fusion proteins onto an Amylose resin (New England Biolabs). This was followed by washing using cold $1 \times$ PBS for GST-fused and MBP-fused proteins and $50 \mathrm{mM}$ imidazole for His-tagged proteins, GST-fused proteins were eluted by $10 \mathrm{mM}$ reduced glutathione, MBP-fused proteins by $10 \mathrm{mM}$ maltose, and His-tagged proteins by $200 \mathrm{mM}$ imidazole. HSP70 was eluted by thrombin digestion to cleave GST fusion protein from the resin. All recombinant proteins were dialyzed against $50 \mathrm{mM}$ HEPES (pH 7.5).

Holdase chaperone assay. The holdase chaperone activity of MBP-GI ${ }^{\mathrm{N}} / \mathrm{GI}^{\mathrm{C}}$ was assayed by measuring its capacity to suppress heat-induced aggregation of Arabidopsis MDH, as a model substrate or MBP-ZTL ${ }^{\mathrm{WT}}$ and MBP-ZTL ${ }^{\mathrm{C} 2 \mathrm{~A}}$, as an authentic GI substrate, prepared as described previously ${ }^{32,66}$. Aggregation of the substrate was monitored in the absence or presence of MBP-GI ${ }^{\mathrm{N}} / \mathrm{GI}^{\mathrm{C}}$ with various molar ratios under heat denaturation at $45^{\circ} \mathrm{C}$ for $15 \mathrm{~min}$ by measuring the turbidity at $340 \mathrm{~nm}$ using a Beckman DU-800 spectrophotometer (Beckman Coulter) attached to a thermostatic cell holder assembly. The light scattering values of each substrate alone at the endpoint $(15 \mathrm{~min}$ ) of incubation was set to $100 \%$, and the absorbance value of each treatment expressed relative to it. All holdase assays were performed in $40 \mathrm{mM}$ HEPES ( $\mathrm{pH}$ 7.5) with HSP70 and BSA used as positive and negative controls, respectively.

Foldase chaperone assay. Foldase chaperone activity was assayed by measuring the capacity to refold chemically denatured G6PDH as a model substrate (Sigma) ${ }^{66}$. G6PDH $(1 \mu \mathrm{M})$ was denatured in $4 \mathrm{M}$ guanidine-HCL $(\mathrm{Gn}-\mathrm{HCl})$ for $2.5 \mathrm{~h}$ at room temperature and refolded in renaturation buffer $(50 \mathrm{mM}$ Tris- $\mathrm{HCl}, \mathrm{pH} 7.5,10 \mathrm{mM}$ ATP, $10 \mathrm{mM} \mathrm{KCl}$, and $2.5 \mathrm{mM} \mathrm{MgCl}_{2}$ ) in the absence (spontaneous refolding) or presence of $\mathrm{GroEL}^{40}$ (as a positive control, Takara), MBP (as a negative control), MBP-GI ${ }^{\mathrm{N}}$, or MBP-GI ${ }^{\mathrm{C}}$. Refolded G6PDH was monitored by measuring the formation of NADPH at $\mathrm{Abs}_{340}$ in assay buffer $(50 \mathrm{mM}$ Tris- $\mathrm{HCl}, \mathrm{pH} 7.5,1 \mathrm{mM}$ NADP) containing $2 \mathrm{mM}$ glucose-6-phosphate (Sigma) as a substrate. The activity was calculated relative to native G6PDH activity (set to 100\%). To examine ZTL refolding activity, we developed a foldase chaperone assay protocol using a substrate (ZTL) translationally fused to glutathione-S-transferase (GST) based on $\mathrm{CDNB}^{42}$. Recombinant GST, GST-ZTL ${ }^{\mathrm{WT}}$, and GST-ZTL ${ }^{\mathrm{C} 82 \mathrm{~A}}(2 \mu \mathrm{M})$ were denatured in $100 \mathrm{mM}$ potassium phosphate $(\mathrm{pH} 6.5)$ at $45^{\circ} \mathrm{C}$ for $3 \mathrm{~h}$. Denatured proteins $(33.3 \mathrm{nM})$ were immediately incubated in the absence (spontaneous refolding) or presence of various combinations of candidate chaperones (His-GI ${ }^{\mathrm{N}}$ or His-GI ${ }^{\mathrm{C}}$ in the absence or presence of HSP90/HSP70) using a combined renaturation and GST assay buffer ( $100 \mathrm{mM}$ potassium phosphate, $\mathrm{pH} 6.5,10 \mathrm{mM}$ ATP, $10 \mathrm{mM} \mathrm{KCl}, 2.5 \mathrm{mM} \mathrm{MgCl}_{2}, 2 \mathrm{mM}$ CDNB and $2 \mathrm{mM}$ GSH). GST activity was followed by measuring the formation of GS-DNB conjugate (a reaction product of GST) at $\mathrm{Abs}_{340}$, and was expressed relative to the activity of undenatured GST, GST-ZTL ${ }^{\mathrm{WT}}$, or GST-ZTL ${ }^{\mathrm{C} 2 \mathrm{~A}}$ (set to $100 \%$ ). Both foldase assays were conducted at $25^{\circ} \mathrm{C}$ with a Beckman DU-800 spectrophotometer attached to a thermostatic cell holder assembly. 
GI oligomerization. Ten-day-old GI:GI-HA plants grown in 12L/12D conditions were harvested at ZT6 and ZT18 for sampling in white light (L) and darkness (D), respectively. The plants were also harvested at ZT18 under blue (B), red (R), and constant white light (LL). Total proteins were homogenized in extraction buffer containing $100 \mathrm{mM}$ Tris- $\mathrm{HCl}(\mathrm{pH} 7.5), 150 \mathrm{mM} \mathrm{NaCl}, 0.5 \%$ (v/v) NP-40, $1 \mathrm{mM}$ EDTA and protease inhibitors ( $1 \mathrm{mM}$ PMSF, $5 \mu \mathrm{g} \mathrm{ml}^{-1}$ leupeptin, $1 \mu \mathrm{g} \mathrm{ml}^{-1}$ aprotinin, $1 \mu \mathrm{g} \mathrm{ml}^{-1}$ pepstatin, $5 \mu \mathrm{g} \mathrm{ml}^{-1}$ antipain, $5 \mu \mathrm{g} \mathrm{ml}^{-1}$ chymostatin, $2 \mathrm{mM}$ $\mathrm{Na}_{2} \mathrm{VO}_{3}, 2 \mathrm{mM} \mathrm{NaF}$, and $50 \mu \mathrm{M} \mathrm{MG132}$ ) in the absence (for non-reducing SDS-PAGE) or presence of DTT (3 mM; for reducing SDS-PAGE). Supernatant was recovered after centrifugation at $10,000 \mathrm{~g}$ for $10 \mathrm{~min}$ at $4{ }^{\circ} \mathrm{C}$. The proteins were separated on $10 \%$ non-reducing SDS-PAGE (without $\beta$-mercaptoethanol in loading buffer) and reducing SDS-PAGE (with $\beta$-mercaptoethanol), and then analyzed by immunoblot analysis to detect GI-HA ${ }^{23}$.

Gel filtration. Ten-day-old Arabidopsis GI:GI-HA, 35S:GI-HA, and gi-2 ztl103 seedlings were harvested as indicated and homogenized in extraction buffer without DTT as above. Supernatant was recovered after centrifugation at $10,000 \mathrm{~g}$ for $10 \mathrm{~min}$ at $4{ }^{\circ} \mathrm{C}$ and filtered through a $0.45 \mu \mathrm{m}$ disk-filter (Advantec). The resulting supernatant ( $1 \mathrm{mg}$ protein) was eluted through a Superdex $200 \mathrm{HR}$ 10/30 column pre-equilibrated with elution buffer $(50 \mathrm{mM}$ Tris-HCl (pH 7.5), $100 \mathrm{mM}$ $\mathrm{NaCl}$, and $0.02 \%$ sodium azide) at a flow-rate of $0.5 \mathrm{ml} \mathrm{min}^{-1}$. The eluted proteins were immediately precipitated with $10 \%(\mathrm{v} / \mathrm{v})$ trichloroacetic acid for $10 \mathrm{~min}$ on ice, washed by $100 \%$ acetone twice and dissolved in urea/SDS buffer. The fractions were separated on SDS-PAGE and analyzed by immunoblot analysis to detect GI-HA, ZTL, and HSP $90^{23,32}$.

Mass spectrometry. Recombinant MBP-GI variants $\left(\mathrm{MBP}-\mathrm{GI}^{\mathrm{N}}\right.$ and $\mathrm{MBP}-\mathrm{GI}^{\mathrm{C}}$ ) were identified by Matrix Assisted Laser Desorption/Ionization Time of Flight/Time of Flight (MALDI-TOF/TOF) Mass Spectroscopy (MS) ${ }^{67}$. Purified recombinant MBP-GI ${ }^{\mathrm{N}}$ and $\mathrm{MBP}-\mathrm{GI}^{\mathrm{C}}$ proteins from E. coli were separated on $10 \%$ SDS-PAGE and stained with Coomassie-brilliant blue. The bands were excised and digested by trypsin $\left(50 \mathrm{ng} \mathrm{ml}^{-1}\right)$. Peptides extraction was done twice with one volume of acetonitrile $(\mathrm{ACN}) /$ water $/ \mathrm{CF}_{3} \mathrm{COOH}(66: 33: 0.1, \mathrm{v} / \mathrm{v} / \mathrm{v})$ solution, sonicated, centrifuged, and dried using speed vacuum. Dried peptides were dissolved in $50 \%(\mathrm{v} / \mathrm{v}) \mathrm{ACN} / 0.1 \%(\mathrm{v} / \mathrm{v})$ trifluoroacetic acid solution. The solution was carefully spotted onto the MALDI-TOF/TOF-MS target plate and analyzed on an ABI 4800 Plus TOF-TOF Mass Spectrometer (AB Sciex). Spectral data were searched using Mascot (version 2.3.0; Matrix Science) and search criteria were-single missing pick, oxidation of methionines, and carbamidomethylation of cysteines. A statistically significant value is $p=0.05$ to search individual peptide ions score.

Yeast two-hybrid. Yeast two-hybrid assay was performed using LexA-based assay system (DupLEX-A; OriGene Technology). The final bait and prey constructs were established by the LR recombinase reaction using each entry clone $\left(\mathrm{HSP} \mathrm{O}^{(32)}\right.$ and $\mathrm{GI}^{(9)}$ ) and Gateway versions of pGilda and pOST4- $5^{(9)}$. Sets of constructs were co-transformed into EGY48 (ura3, his3, trp1, leu:6 LexAop-LEU2) containing lacZ reporter plasmid pSH18-34. Yeast transformants were selected on glucose-based synthetic minimal medium (SD; $0.67 \%$ yeast nitrogen base, $2 \%$ glucose (wt/vol), and amino acid dropout solution) deficient in histidine, tryptophan, and uracil (-HIS-TRP-URA) and protein interaction tests were performed after protein induction on galactose and raffinose-based SD-HIS-TRP-URA media.

In vivo maturation assay for LUC and ZTL-LUC. Arabidopsis seedlings were grown for $10 \mathrm{~d}$ in a $12-\mathrm{h} \mathrm{L} / 12-\mathrm{h}$ D photoperiod and then harvested at ZT1 $(1 \mathrm{~h}$ after lights on) and ZT13 ( $1 \mathrm{~h}$ after lights off). Protein extracts were prepared using extraction buffer (50 mM Tris-Cl, pH 7.5, 1 mM EDTA, 1 mM dithiothreitol, $1 \mathrm{mM}$ phenylmethylsulfonyl fluoride, $5 \mathrm{\mu g} \mathrm{ml}^{-1}$ leupeptin, $1 \mu \mathrm{g} \mathrm{ml}^{-1}$ aprotinin, $1 \mu \mathrm{g} \mathrm{ml}^{-1}$ pepstatin, $5 \mu \mathrm{g} \mathrm{ml}^{-1}$ antipain, $5 \mu \mathrm{g} \mathrm{ml}^{-1}$ chymostatin, $50 \mu \mathrm{M} \mathrm{MG} 132,50 \mu \mathrm{M}$ MG115, and $50 \mu \mathrm{M}$ ALLN). Protein extracts from 35S:ZTL-LUC (Col) harvested at ZT13 were diluted with untransformed Col protein extracts by a factor of 1-3 to obtain similar LUC activity levels for 35S:ZTL-LUC in the Col and gi-201 backgrounds. Luciferase activity of ZTL-LUC from protein extracts was measured using Luciferase assay system (Promega) and 96-well dual-injection luminometer (Centro LB960; Berthold Technologies), according to the manufacturer's instructions and normalized with adenosine kinase (ADK) protein levels, which was determined by SDS-PAGE and subsequent immunodetection using anti-ADK antibody $(1: 40,000)^{9}$. Linear dynamic ranges for luciferase activity was confirmed by using serial diluted samples with the 35S:ZTL-LUC (Col) harvested at ZT13.

Protein levels of ZTL-LUC were determined by immunoblot analysis from TCA concentrated proteins from the same protein extracts using purified anti-LUC antibody, and further normalized to ADK protein levels. Specific activity of LUC was determined by the ratio of luciferase activity (normalized to ADK protein levels) to the level of LUC protein levels (normalized to ADK protein levels). For each biological trial the value for each non-ZT13 Col WT sample (Fig. 3a, b) were determined as a relative value calculated by normalization to the reference samples (Col_ZT13, set to 1 for each trial). The same was done for Fig. 3c except normalization was to ZT1 or ZT13 among the different genotypes. Purified anti-LUC antibody was generated from anti-LUC antibody (Sigma, L0159) by immunoaffinity purification against bacterially expressed LUC immobilized to poly (vinylidene difluoride) membrane by standard techniques.

Immunoprecipitation analyses. 10-d-old Arabidopsis seedling were grown in 12-h $\mathrm{L} / 12$-h D photoperiod and harvested at ZT13 on MS plates was subjected to in vivo protein cross-linking ${ }^{22}$. Immunoprecipitation was performed using anti-PAP antibody (Sigma, P1291) and protein visualization was performed by SDS-PAGE separation, followed by immunodetection using anti-HSP90 (1:50,000), anti-ZTL (1:500), and anti-PAP antibody $(1: 1000)^{9}$. Uncropped versions of these and other gels and blots shown in the figures and Supplementary Information are found in Supplementary Fig. 15.

Sequential immunoprecipitation. GI-TAP, HSP90-HA, and ZTL-GFP were constitutively co-expressed in $N$. benthamiana in all pairwise and triple combinations by Agrobacterium infiltration. Proteins were extracted and incubated with IgG-agarose (Sigma) for $1 \mathrm{~h}$ at $4{ }^{\circ} \mathrm{C}^{9}$. The harvested immune complexes were washed three times with buffer and GI-TAP complexes were released from IgG beads using $3 \mathrm{C}$ protease (2 units, Precision Protease, GE Healthcare Life Science) for $3 \mathrm{~h}$ at $4{ }^{\circ} \mathrm{C}$. Supernatants were incubated for $2 \mathrm{~h}$ at $4{ }^{\circ} \mathrm{C}$ with protein A agarose (Invitrogen), which had been pre-incubated with anti-GFP mouse monoclonal antibody (Molecular Probes) at $4{ }^{\circ} \mathrm{C}$. The resulting immune complexes (ZTL-GFP) were washed four times, resuspended in SDS-PAGE sample buffer, briefly heated $\left(93^{\circ} \mathrm{C}, 5 \mathrm{~min}\right)$ and subjected to SDS/PAGE and immunoblotting.

Co-immunoprecipitation assay. Agrobacteria containing HA-tagged GI full length (FL), $\mathrm{GI}^{\mathrm{N}}$, or $\mathrm{GI}^{\mathrm{C}}$ were co-infiltrated with GFP-tagged wild-type (WT) ZTL or ZTL ${ }^{\mathrm{C} 22 \mathrm{~A}}$ into 3-4 week old $N$. benthamiana leaves. Samples were collected 3 days after infiltration, tissue ground in liquid nitrogen and protein extraction performed ${ }^{68}$. Immunoprecipitation was performed with HA antibody (Roche; 3F10) and immunoblots were probed with anti-HA (1:2000) and anti-GFP antibodies (Abcam; ab6556, 1:5000).

In planta protein stabilization assay. Approximately $4.5 \times 10^{5}$ protoplasts from 4-week-old Arabidopsis thaliana gi-201 were used to transform with appropriate vectors $^{62}$. After transfection protoplasts were incubated under dim white light for $26 \mathrm{~h}$ at $22^{\circ} \mathrm{C}$ and then collected by centrifugation at $845 \mathrm{~g}$ for $5 \mathrm{~s}$. Supernatants were removed gently and the remaining protoplasts were frozen in liquid nitrogen followed by protein extraction using protein extraction buffer $(100 \mathrm{mM}$ Tris-Cl, $\mathrm{pH}$ $7.5,150 \mathrm{mM} \mathrm{NaCl}, 1 \mathrm{mM}$ EDTA, $0.5 \%$ NP-40, $1 \mathrm{mM}$ DTT, $1 \mathrm{mM} \mathrm{PMSF}, 5 \mu \mathrm{g} \mathrm{ml}^{-1}$ leupeptin, $1 \mu \mathrm{g} \mathrm{ml}^{-1}$ aprotinin, $1 \mu \mathrm{g} \mathrm{ml}^{-1}$ pepstatin, $5 \mu \mathrm{g} \mathrm{m}^{-1}$ antipain, $5 \mu \mathrm{g} \mathrm{m}^{-1}$ chymostatin, $2 \mathrm{mM} \mathrm{NaVO}, 2 \mathrm{mM} \mathrm{NaF}, 50 \mu \mathrm{M}$ MG132, $50 \mu \mathrm{M}$ MG115, $50 \mu \mathrm{M}$ ALLN). Proteins were separated on $8 \%$ of SDS-PAGE gel and detected by HA and GFP antibodies as described above.

Data availability. The authors declare that all data supporting the findings of this study are available within the manuscript and its Supplementary Information files are available from the corresponding author upon request.

Received: 13 December 2015 Accepted: 17 November 2016 Published online: 23 February 2017

\section{References}

1. Hsu, P. Y. \& Harmer, S. L. Wheels within wheels: the plant circadian system. Trends Plant. Sci. 19, 240 (2014).

2. Tataroglu, O. \& Emery, P. The molecular ticks of the Drosophila circadian clock. Curr. Opin. Insect. Sci. 7, 51 (2015).

3. Seo, P. J. \& Mas, P. Multiple layers of posttranslational regulation refine circadian clock activity in Arabidopsis. Plant. Cell 26, 79 (2014).

4. Crane, B. R. \& Young, M. W. Interactive features of proteins composing eukaryotic circadian clocks. Annu. Rev. Biochem. 83, 191 (2014).

5. Mas, P., Kim, W. Y., Somers, D. E. \& Kay, S. A. Targeted degradation of TOC1 by ZTL modulates circadian function in Arabidopsis thaliana. Nature 426, 567 (2003).

6. Kiba, T., Henriques, R., Sakakibara, H. \& Chua, N. H. Targeted degradation of PSEUDO-RESPONSE REGULATOR5 by an SCF ${ }^{\text {ZTL }}$ complex regulates clock function and photomorphogenesis in Arabidopsis thaliana. Plant. Cell 19, 2516 (2007).

7. Fujiwara, S. et al. Post-translational regulation of the Arabidopsis circadian clock through selective proteolysis and phosphorylation of pseudo-response regulator proteins. J. Biol. Chem. 283, 23073 (2008).

8. Ito, S., Song, Y. H. \& Imaizumi, T. LOV domain-containing F-box proteins: light-dependent protein degradation modules in Arabidopsis. Mol. Plant. 5, 573 (2012). 
9. Kim, W. Y. et al. ZEITLUPE is a circadian photoreceptor stabilized by GIGANTEA in blue light. Nature 449, 356 (2007).

10. Fowler, S. et al. GIGANTEA: a circadian clock-controlled gene that regulates photoperiodic flowering in Arabidopsis and encodes a protein with several possible membrane-spanning domains. EMBO. J. 18, 4679 (1999).

11. Park, D. et al. Control of circadian rhythms and photoperiodic flowering by the Arabidopsis GIGANTEA gene. Science 285, 1579 (1999).

12. Kim, W. Y., Geng, R. \& Somers, D. E. Circadian phase-specific degradation of the F-box protein ZTL is mediated by the proteasome. Proc. Natl Acad. Sci. USA 100, 4933 (2003).

13. Gagic, M., Faville, M., Kardailsky, I. \& Putterill, J. Comparative genomics and functional characterisation of the GIGANTEA gene from the temperate forage perennial ryegrass Lolium perenne. Plant. Mol. Biol. Rep. 33, 1098 (2015).

14. Huq, E., Tepperman, J. M. \& Quail, P. H. GIGANTEA is a nuclear protein involved in phytochrome signaling in Arabidopsis. Proc. Natl. Acad. Sci. USA 97, 9789 (2000).

15. Mishra, P. \& Panigrahi, K. C. GIGANTEA-an emerging story. Front. Plant. Sci. 6, 8 (2015).

16. Dalchau, N. et al. The circadian oscillator gene GIGANTEA mediates a longterm response of the Arabidopsis thaliana circadian clock to sucrose. Proc. Natl. Acad. Sci. USA 108, 5104 (2011).

17. Kim, W. Y. et al. Release of SOS2 kinase from sequestration with GIGANTEA determines salt tolerance in Arabidopsis. Nat. Commun. 4, 1352 (2013).

18. Sawa, M., Nusinow, D. A., Kay, S. A. \& Imaizumi, T. FKF1 and GIGANTEA complex formation is required for day-length measurement in Arabidopsis. Science 318, 261 (2007).

19. Martin-Tryon, E. L., Kreps, J. A. \& Harmer, S. L. GIGANTEA acts in blue light signaling and has biochemically separable roles in circadian clock and flowering time regulation. Plant. Physiol. 143, 473 (2007).

20. Mizoguchi, T. et al. Distinct roles of GIGANTEA in promoting flowering and regulating circadian rhythms in Arabidopsis. Plant. Cell 17, 2255 (2005).

21. Gould, P. D. et al. The molecular basis of temperature compensation in the Arabidopsis circadian clock. Plant. Cell 18, 1177 (2006).

22. Kim, J., Geng, R., Gallenstein, R. A. \& Somers, D. E. The F-box protein ZEITLUPE controls stability and nucleocytoplasmic partitioning of GIGANTEA. Development 140, 4060 (2013).

23. David, K. M., Armbruster, U., Tama, N. \& Putterill, J. Arabidopsis GIGANTEA protein is post-transcriptionally regulated by light and dark. FEBS Lett. 580, 1193 (2006)

24. Kim, Y. et al. ELF4 regulates GIGANTEA chromatin access through subnuclear sequestration. Cell Rep. 3, 671 (2013).

25. Yu, J. W. et al. COP1 and ELF3 control circadian function and photoperiodic flowering by regulating GI stability. Mol. Cell 32, 617 (2008).

26. Lee, G. J. Assaying proteins for molecular chaperone activity. Methods Cell Biol. 50, 325 (1995).

27. Kim, Y. E., Hipp, M. S., Bracher, A., Hayer-Hartl, M. \& Hartl, F. U. Molecular chaperone functions in protein folding and proteostasis. Annu. Rev. Biochem. 82, 323 (2013).

28. Chang, H. C., Tang, Y. C., Hayer-Hartl, M. \& Hartl, F. U. SnapShot: molecular chaperones, Part I. Cell 128, 212 (2007).

29. Tang, Y. C., Chang, H. C., Hayer-Hartl, M. \& Hartl, F. U. SnapShot: molecular chaperones, Part II. Cell 128, 412 (2007)

30. Blatch, G. L. \& Edkins, A. L. (eds). Networking of Chaperones by CoChaperones, Subcellular Biochemistry Vol. 78, 1-276 (Springer International Publishing Switzerland, 2015).

31. Echtenkamp, F. J. \& Freeman, B. C. Expanding the cellular molecular chaperone network through the ubiquitous cochaperones. Biochim. Biophys. Acta. 1823, 668 (2012).

32. Kim, T. S. et al. HSP90 functions in the circadian clock through stabilization of the client F-box protein ZEITLUPE. Proc. Natl. Acad. Sci. USA 108, 16843 (2011).

33. Veinger, L., Diamant, S., Buchner, J. \& Goloubinoff, P. The small heat-shock protein IbpB from Escherichia coli stabilizes stress-denatured proteins for subsequent refolding by a multichaperone network. J. Biol. Chem. 273, 11032 (1998).

34. Sharma, S. K., Christen, P. \& Goloubinoff, P. Disaggregating chaperones: an unfolding story. Curr. Protein. Pept. Sci. 10, 432 (2009).

35. Haslbeck, M. \& Buchner, J. Assays to characterize molecular chaperone function in vitro. Methods Mol. Biol. 1292, 39 (2015).

36. Lee, G. J., Roseman, A. M., Saibil, H. R. \& Vierling, E. A small heat shock protein stably binds heat-denatured model substrates and can maintain a substrate in a folding-competent state. EMBO. J. 16, 659 (1997).

37. Hansen, J. E. \& Gafni, A. Thermal switching between enhanced and arrested reactivation of bacterial glucose-6-phosphate dehydrogenase assisted by GroEL in the absence of ATP. J. Biol. Chem. 268, 21632 (1993).

38. Sanz-Barrio, R. et al. Chaperone-like properties of tobacco plastid thioredoxins f and m. J. Exp. Bot. 63, 365 (2012).
39. Hayer-Hartl, M., Bracher, A. \& Hartl, F. U. The GroEL-GroES chaperonin machine: a nano-cage for protein folding. Trends Biochem. Sci. 41, 62 (2016).

40. Park, J. H. et al. Heat-induced chaperone activity of serine/threonine protein phosphatase 5 enhances thermotolerance in Arabidopsis thaliana. New. Phytol. 191, 692 (2011).

41. Hutchinson, M. H. \& Chase, H. A. Adsorptive refolding of histidine-tagged glutathione S-transferase using metal affinity chromatography. J. Chromatogr. A. 1128, 125 (2006).

42. Cha, J. Y., Kim, M., Kim, W. Y. \& Kim, M. Development of in vitro HSP90 foldase chaperone assay using a GST-fused real-substrate. ZTL (ZEITLUPE) $\mathbf{5 8}$ 236 (2015)

43. Karagoz, G. E. \& Rudiger, S. G. Hsp90 interaction with clients. Trends Biochem. Sci. 40, 117 (2015).

44. Freeman, B. C., Michels, A., Song, J., Kampinga, H. H. \& Morimoto, R. I. Analysis of molecular chaperone activities using in vitro and in vivo approaches. Methods Mol. Biol. 99, 393 (2000).

45. Walther, T. V. \& Maddalo, D. Intracellular refolding assay. J. Vis. Exp. 59, 3540 (2012).

46. Bepperling, A. et al. Alternative bacterial two-component small heat shock protein systems. Proc. Natl. Acad. Sci. USA 109, 20407 (2012).

47. Black, M. M., Stockum, C., Dickson, J. M., Putterill, J. \& Arcus, V. L. Expression, purification and characterisation of GIGANTEA: a circadian clock-controlled regulator of photoperiodic flowering in plants. Protein. Expr. Purif. 76, 197 (2011).

48. Li, J. \& Buchner, J. Structure, function and regulation of the Hsp90 machinery Biomed. J. 36, 106 (2013).

49. Taipale, M., Jarosz, D. F. \& Lindquist, S. HSP90 at the hub of protein homeostasis: emerging mechanistic insights. Nat. Rev. Mol. Cell Biol. 11, 515 (2010).

50. Rohl, A., Rohrberg, J. \& Buchner, J. The chaperone Hsp90: changing partners for demanding clients. Trends Biochem. Sci. 38, 253 (2013).

51. Li, J., Soroka, J. \& Buchner, J. The Hsp90 chaperone machinery: conformational dynamics and regulation by co-chaperones. Biochim. Biophys. Acta. 1823, 624 (2012).

52. Prodromou, C. The "active life" of Hsp90 complexes. Biochim. Biophys. Acta. 1823, 614 (2012)

53. Taipale, M. et al. A quantitative chaperone interaction network reveals the architecture of cellular protein homeostasis pathways. Cell 158, 434 (2014)

54. Taipale, M. et al. Quantitative analysis of HSP90-client interactions reveals principles of substrate recognition. Cell 150, 987 (2012).

55. Genest, O., Hoskins, J. R., Camberg, J. L., Doyle, S. M. \& Wickner, S. Heat shock protein 90 from Escherichia coli collaborates with the DnaK chaperone system in client protein remodeling. Proc. Natl. Acad. Sci. USA 108, 8206 (2011).

56. Takahashi, S. \& Mendelsohn, M. E. Synergistic activation of endothelial nitric-oxide synthase (eNOS) by HSP90 and Akt: calcium-independent eNOS activation involves formation of an HSP90-Akt-CaM-bound eNOS complex. J. Biol. Chem. 278, 30821 (2003).

57. Panaretou, B., et al. Activation of the ATPase activity of hsp90 by the stress-regulated cochaperone aha1. Mol. Cell 10, 1307 (2002)

58. Kadota, Y. \& Shirasu, K. The HSP90 complex of plants. Biochim. Biophys. Acta. 1823, 689 (2012).

59. Breiman, A. Plant Hsp90 and its co-chaperones. Curr. Protein. Pept. Sci. 15, 232 (2014).

60. Freeman, B. C., Toft, D. O. \& Morimoto, R. I. Molecular chaperone machines chaperone activities of the cyclophilin Cyp-40 and the steroid aporeceptorassociated protein p23. Science 274, 1718 (1996).

61. Echtenkamp, F. J. et al. Global functional map of the p23 molecular chaperone reveals an extensive cellular network. Mol. Cell 43, 229 (2011).

62. Kim, J. \& Somers, D. E. Rapid assessment of gene function in the circadian clock using artificial microRNA in Arabidopsis mesophyll protoplasts. Plant. Physiol. 154, 611 (2010).

63. Curtis, M. D. \& Grossniklaus, U. A gateway cloning vector set for high-throughput functional analysis of genes in planta. Plant. Physiol. 133, 462 (2003).

64. Kim, Y. et al. GIGANTEA and EARLY FLOWERING 4 in Arabidopsis exhibit differential phase-specific genetic influences over a diurnal cycle. Mol. Plant. 5, 678 (2012)

65. Han, L., Mason, M., Risseeuw, E. P., Crosby, W. L. \& Somers, D. E. Formation of an SCF complex is required for proper regulation of circadian timing. Plant. J. 40, 291 (2004).

66. Cha, J. Y. et al. Functional characterization of orchardgrass cytosolic Hsp70 (DgHsp70) and the negative regulation by $\mathrm{Ca} 2+/ \mathrm{AtCaM} 2$ binding. Plant. Physiol. Biochem. 58, 29 (2012).

67. Kwon, Y. S. et al. Proteomic analyses of the interaction between the plant-growth promoting rhizobacterium Paenibacillus polymyxa E681 and Arabidopsis thaliana. Proteomics 16, 122 (2016). 
68. Wang, L., Kim, J. \& Somers, D. E. Transcriptional corepressor TOPLESS complexes with pseudoresponse regulator proteins and histone deacetylases to regulate circadian transcription. Proc. Natl. Acad. Sci. USA 110, 761 (2013).

\section{Acknowledgements}

This work was supported by National Institutes of Health Grant R01GM093285 (D.E.S.) and by grants from the Next-Generation BioGreen21 Program (SSAC, PJ01106901),

Rural Development Administration, Republic of Korea (W.-Y.K.).

\section{Author contributions}

J.-Y.C., J.K., T.-S.K., Q.Z., L.W., W.-Y.K designed and performed the experiments, collected data, and analyzed the results. D.E.S. designed the project, some experiments, and wrote the manuscript. S.Y.L. contributed novel reagents and contributed to discussions.

\section{Additional information}

Supplementary Information accompanies this paper at doi:10.1038/s41467-016-0014-9.
Competing financial interests: The authors declare no competing financial interests.

Reprints and permission information is available online at http://npg.nature.com/ reprintsandpermissions/

Publisher's note: Springer Nature remains neutral with regard to jurisdictional claims in published maps and institutional affiliations.

This work is licensed under a Creative Commons Attribution 4.0 International License. The images or other third party material in this article are included in the article's Creative Commons license, unless indicated otherwise in the credit line; if the material is not included under the Creative Commons license, users will need to obtain permission from the license holder to reproduce the material. To view a copy of this license, visit http://creativecommons.org/licenses/by/4.0/

(C) The Author(s) 2017 


\section{Editor's Summary}

The plant-specific GIGANTEA protein regulates the circadian clock by stabilizing the F-box protein ZEITLUPE via an unknown mechanism. Here Cha et al. show that GIGANTEA has intrinsic chaperone activity and can facilitate ZEITLUPE maturation by acting synergistically with HSP90. 